\title{
PENGARUH PENGETAHUAN DAN PENDIDIKAN TERHADAP SELF EFFICACY IBU DALAM MELAKUKAN BABY MASSAGE DAN BABY GYM DI DESA MADEGONDO KECAMATAN GROGOL KABUPATEN SUKOHARJO
}

\author{
Gipfel Remedina ${ }^{1)}$, Fitria Hayu Palupi ${ }^{2)}$ \\ ${ }^{1}$ STIKes Mitra Husada Karanganyar \\ ${ }^{2}$ STIKes Mitra Husada Karanganyar \\ Email: gipfelremedina@gmail.com
}

\begin{abstract}
ABSTRAK
Pijat bayi biasa disebut dengan stimulus touch. Pijat bayi dapat diartikan sebagai sentuhan komunikasi yang nyaman antara ibu dan bayi. Jadi, pijat bayi ini merupakan suatu pengungkapan rasa kasih sayang antara orang tua dengan anak lewat sentuhan pada kulit yang dapat memberikan dampak yang luar biasa. Sentuhan dan pijat pada bayi setelah kelahiran dapat memberikan jaminan adanya kontak tubuh berkelanjutan yang dapat mempertahankan perasaan nyaman pada bayi. Sentuhan dan pijat menghasilkan perubahan fisiologis yang menguntungkan berupa peningkatan pertumbuhan, peningkatan daya tahan tubuh, dan kecerdasan emosi lebih baik. Penelitian ini bertujuan untuk menganalisa pengaruh pengetahuan dan Pendidikan tehadap self efficacy ibu dalam melakukan baby massage dan baby gym di Desa Madegondo, Kecamatan Grogol, Kabupaten Sukoharjo. Jenis penelitian ini adalah pendekatan kuantitatif dengan desain cross sectional. Populasi penelitian ini adalah seluruh ibu yang memiliki bayi balita di Desa Madegondo Kecamatan Grogol Kabupaten Sukoharjo sejumlah 29 orang. Sampel penelitian berjumlah 29 orang, di ambil secara total sampling. Variable independent penelitian ini adalah pengetahuan dan Pendidikan dan variable dependen penelitian ini adalah self efficacy ibu dalam melakukan baby massage dan baby gym. Intrumen penelitian menggunakan kuesioner. Pengolahan data Editing, Coding, Scoring, Tabulating. Hasil penelitian menunjukkan tingkat pendidikan akademi memiliki tingkat self efficacy baik sebanyak 37,93\% (11 responden), sedangkan tingkat pengetahuan sangat baik memiliki tingkat self efficacy baik sebanyak 31,03\% (9 responden). Uji statistic menunjukkan bahwa Hasil penelitian $F_{\text {hitung }}$ lebih kecil dari pada $F_{\text {tabel }}(0,385<4,21<7,67$ ). maka disimpulkan Ho diterima dan Ha ditolak. yang artinya tidak ada hubungan antara tingkat pengetahuan dan pendidikan dengan self efficacy. Kesimpulan penelitian ini tidak ada hubungan antara tingkat pengetahuan dan Pendidikan dengan self efficacy ibu dalam melakukan baby massage dan baby gym di desa madegondo kecamatan grogolkabupaten sukoharjo
\end{abstract}

Kata Kunci: Pengetahuan, Self efficacy, baby massage dan baby gym

\section{ABSTRACT}

Baby massage is commonly referred to as stimulus touch. Baby massage can be interpreted as a touch of comfortable communication between mother and baby. So, this baby massage is a disclosure of affection between parents and children through touch on the skin that can have an extraordinary impactbias a. Touch and massage in the baby after birth can guarantee the existence of continuous body contact that can maintain a feeling of comfort in the baby. Touch and massage result in beneficial physiological changes in the form of increased growth, increased endurance, and better emotional intelligence. This study aims to analyze the influence of knowledge and education tehadap self efficacy mother in doing baby massage and baby gym in Madegondo Village, Grogol District, Sukoharjo Regency. This type of research is a quantitative approach with cross sectional design. The population of this study is all mothers who have a toddler baby in madegondo village grogol district Sukoharjo district numbered 29 people. The research sample amounted to 29 people, taken in total sampling. Variable independent research is knowledge and Education and variable dependent research is self efficacy of mothers in doing baby massage and baby gym. Intrumen research using questionnaires. Data Processing Editing, Coding, Scoring, Tabulating. The results showed the level of academy education has a good level of self efficacy as much as 37.93\% ( 11 respondents), while the level of excellent knowledge has a good level of self efficacy as much as 31.03\% ( 9 respondents). Statistics tests showed that the $F$ study results counted smaller than the $F$ table $(0.385<4.21<7.67)$. then concluded Ho was accepted and Ha rejected. which means there is no relationship between the level 
of knowledge and education with self efficacy. The conclusion of this study is no relationship between the level of knowledge and education with self efficacy of mothers in doing baby massage and baby gym in the village madegondo district grogolkabupaten sukoharjo

Keyword: Knowlage, Self efficacy, baby massage dan baby gym

\section{PENDAHULUAN}

Pijat bayi biasa disebut dengan stimulus touch. Pijat bayi dapat diartikan sebagai sentuhan komunikasi yang nyaman antara ibu dan bayi. Jadi, pijat bayi ini merupakan suatu pengungkapan rasa kasih sayang antara orang tua dengan anak lewat sentuhan pada kulit yang dapat memberikan dampak yang luar biasa. (Dewi, 2012)

Pijat bayi adalah terapi sentuhan tertua dan terpopuler yang dikenal manusia yang juga merupakan seni perawatan kesehatan dan pengobatan yang dipraktikkan sejak berabadabad silam. Pijat bayi telah lama dilakukan hampir diseluruh dunia termaksud di Indonesia diwariskan secara turun temurun. Sentuhan dan pijat pada bayi setelah kelahiran dapat memberikan jaminan adanya kontak tubuh berkelanjutan yang dapat mempertahankan perasaan nyaman pada bayi. Sentuhan dan pijat menghasilkan perubahan fisiologis yang menguntungkan berupa peningkatan pertumbuhan, peningkatan daya tahan tubuh, dan kecerdasan emosi lebih baik. (Roesli, 2008)

Pijat bayi terbukti memberikan stimulus pada hormon didalam tubuh yang mengatur fungsi-fungsi seperti nafsu makan, tidur, ingatan dan belajar serta pengatur temperatur, mood, perilaku, fungsi pembuluh darah, kontraksi otot, pengatur sistem endokrin, pengatur metabolisme, pertumbuhan dan depresi. Bahkan pijat bayi dapat meningkatkan berat badan bayi, membantu bayi bisa tidur dengan nyenyak, menambah nafsu makan, dan meningkatkan bayi .untuk berkonsentrasi. Hal ini dapat bermanfaat untuk tumbuh dan kembang bayi selanjutnya. (Peter Walker, 2011)

Menurut hasil studi pendahuluan pada bulan Februari 2021 di Desa Madegondo Kecamatan Grogol Kabupaten Sukoharjo terdapat ibu yang mempunyai bayi datang untuk memijatkan bayinya beberapa diantaranya ada yang memijatkan bayinya jika rewel ataupun sakit. Sebagian ibu ada yang sudah mengetahui tentang manfaat dari pijat bayi bahwa bisa membantu pertumbuhan dan perkembangan pada bayi dan ada juga yang belum mengetahui manfaat pijat bayi tersebut. Hasil dari wawancara ada 3 orang ibu yang sudah mengetahui manfaat dari pijat bayi serta teratur memijatkan bayinya dan 3 orang ibu yang belum berani memijat bayinya, meskipun sudah mengetahui tekniknya namun merasa kurang percaya diri untuk melakukan pemijatan pada bayi.

Berdasarkan latar belakang di atas, peneliti tertarik untuk melakukan penelitian mengenai pengaruh pengetahuan dan pendidikan dengan self efficacy ibu dalam melakukan baby massage dan baby gym.

\section{METODE}

Rancangan penelitian yang digunakan adalah pendekatan kuantitatif dengan desain cross sectional. Desain cross sectional merupakan suatu penelitian untuk mempelajari korelasi dengan cara pendekatan, observasi ataupun pengumpulan data sekaligus pada saat itu juga.

Populasi dalam penelitian ini adalah ibu yang memiliki bayi dan balita di dusun madegondo, grogol sukoharjo. Dalam penelitian ini di ambil sejumlah 29 responden. Sampel di ambil dengan dengan tehnik total sampling. Instrument penelitian menggunakan kuesioner.

Penelitian ini dilakukan di desa Madegondo, Grogol, Sukoharjo.

Pengolaham data meliputi cleaning, coding, skoring, entering. Analisa data univariat dan bivariate

\section{HASIL}

Pelaksanaan penelitian ini dilakukan di dusun Madegondo, Grogol Sukoharjo dengan responden berjumlah 29 responden.

1. Karakteristik responden

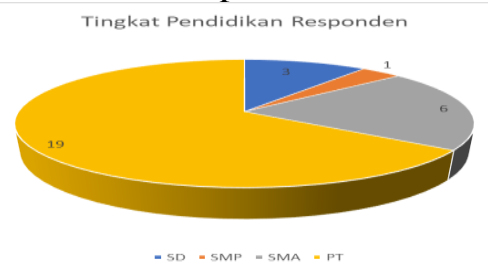

Gambar 1. Tingkat Pendidikan Responden

Dari hasil penelitian terdapat 29 responden dengan tingkat pendidikan SD sebanyak 3 
orang ( $10.3 \%)$, tingkat pendidikan SMP sebanyak 1 orang (3.4\%), tingkat pendidikan SMA sebanyak 6 orang (20.7\%), sedangkan untuk tingkat pendidikan akademi sebanyak 19 orang $(65.5 \%)$.

2. Tingkat pengetahuan responden tentang baby massage

\section{Tingkat Pengetahuan}

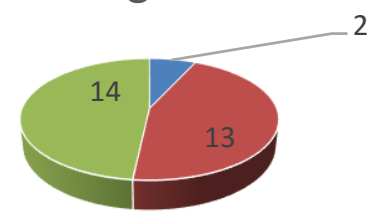

- Cukup Baik - Baik - Sangat Baik .

Gambar 2. Tingkat pengetahuan responden tentang baby massage

Adapun tingkat pengetahuan responden dikategorikan dengan nilai responden dalam mengisi kuesioner dengan kategori jawaban benar yaitu 76-100 = Sangat baik; 56-75 = Baik; 40-55 = Cukup baik; 0-39 = kurang.

Dari hasil penelitian terdapat tingkat pengetahuan cukup baik sebanyak 2

Tabel 1. Tingkat pendidikan dan tingkat pengetahuan responden

\begin{tabular}{|c|c|c|c|c|}
\hline \multirow[t]{2}{*}{ Pendidikan } & \multicolumn{3}{|c|}{ Tingkat Pengetahuan } & \multirow[t]{2}{*}{ Total } \\
\hline & Cukup Baik & Baik & Sangat Baik & \\
\hline $\begin{array}{l}\text { Akademi / } \\
\text { PT }\end{array}$ & 2 & 7 & 10 & 19 \\
\hline SMA & 0 & 3 & 3 & 6 \\
\hline SMP & 0 & 1 & 0 & 1 \\
\hline SD & 0 & 2 & 1 & 3 \\
\hline
\end{tabular}

Sumber: data primer 2021

Berdasarkan data di atas data penelitian didapatkan bahwa tingkat pendidikan akademi memiliki tingkat pengetahuan sangat baik sebanyak 34,48 \% (10 responden)

Tabel 2. Hubungan tingkat Pendidikan dan tingkat self efficacy

\begin{tabular}{lccccc}
\hline Pendidikan & \multicolumn{4}{c}{ Self Efficacy } & Total \\
& Kurang & Cukup Baik & Baik & Sangat Baik & \\
\hline Akademi & 2 & 5 & 11 & 1 & 19 \\
/ PT & & 2 & 3 & 0 & 6 \\
SMA & 1 & 0 & 1 & 0 & 1 \\
SMP & 0 & 0 & 2 & 1 & 3 \\
SD & 1 & &
\end{tabular}

Sumber: Data primer 2021

Hasil data penelitian didapatkan bahwa tingkat pendidikan akademi memiliki tingkat self efficacy baik sebanyak $37,93 \%$ (11 responden) responden (6.9\%); Baik sebanyak 13 responden $(44.8 \%)$ dan sangat baik sebesar 14 responden $(48.3 \%)$.

3. Tingkat self efficacy

\section{Self Efficacy}

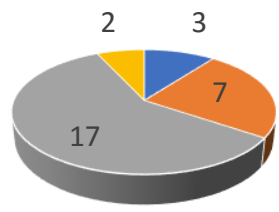

- Kurang - Cukup Baik = Baik - Sangat Baik

\section{Gambar 3. Self efficacy}

Adapun hasil pengambilan data tentang self efficacy adalah sebagai berikut: terdapat 3 responden dengan kategori kurang (10.3\%), 7 responden kategori cukup baik ( $24.1 \%), 17$ responden kategori baik $(56,6 \%)$ dan 2 orang kategori sangat baik (6,9\%).

4. Hubungan Tingkat Pendidikan dan Tingkat pengetahuan

5. Hubungan tingkat Pendidikan dan tingkat self efficacy 
Tabel 3. Hubungan Tingkat pengetahuan dan tingkat self efficacy

\begin{tabular}{lccccc}
\hline Tingkat & & \multicolumn{3}{c}{ Self Efficacy } & Total \\
Pengetahuan & Kurang & Cukup Baik & Baik & Sangat Baik & \\
\hline Kurang & 0 & 0 & 0 & 0 & 0 \\
Cukup Baik & 0 & 1 & 1 & 0 & 2 \\
Baik & 3 & 2 & 7 & 1 & 13 \\
Sangat Baik & 0 & 4 & 9 & 1 & 14 \\
\hline
\end{tabular}

Sumber: data primer 2021

Hasil data penelitian didapatkan bahwa tingkat pengetahuan sangat baik memiliki tingkat self efficacy baik sebanyak 31,03\% (9 responden), tingkat pengetahuan baik dengan self efficacy baik sebanyak $24,13 \%$ (7 responden), tingkat pengetahuan sangat baik dengan self efficacy cukup baik sebanyak 13,79\% (4 responden), tingkat penegtahuan baik dengan self efficacy kurang sebanyak $10,34 \%$ (3 responden) dan tingkat pengetahuan cukup baik dengan self efficacy cukup baik sebanyak $3,4 \% \quad$ (1 responden), tingkat pengetahuan cukup baik dengan self efficacy baik sebanyak 3,4\% (1 responden), tingkat pengetahuan baik dengan self efficacy sangat baik sebanyak 3,4\% (1 responden), tingkat pengetahuan sangat baik dengan self efficacy sangat baik sebanyak $3,4 \%$ (1 responden).

7. Analisa Data

a. Normalitas Data

Uji normalitas bertujuan untuk mengetahui apakah model regresi mempunyai distribusi sebaran data normal atau tidak. Uji normalitas data penelitian ini menggunakan kolmogorof Smirnov yang dihitung dengan bantuan program aplikasi computer SPSS versi 16. Pengambilan keputusan berdasarkan nilai probabilitas yaitu jika probabilitas > 0,05 maka data berdistribusi normal. Demikian sebaliknya, apabila nilai probabilitas < 0,05 maka data berdistribusi tidak normal

Tabel 4. Normalitas Data

\begin{tabular}{llll}
\hline & Kolmogorov smirnov $z$ & Probabilitas & Keputusan \\
\hline Tingkat Pengetahuan & 1.004 & 0,265 & Normal \\
Tingkat self eficacy & 1,097 & 0,180 & Normal \\
\hline
\end{tabular}

\section{Sumber: Data Primer 2021}

Dari tabel dapat diketahui bahwa hasil uji kolmogorov- smirnov $z$ pada tingkat pendidikan adalah 1, 113 dan nilai probabilitas tingkat pendidikan adalah 0,168. Simpulan uji normalitas data pada tingkat pendidikan adalah normal, karena lebih dari $0,05(0,168>0,05)$.

Hasil uji kolmogorov-smirnov $z$ pada Tingkat Pengetahuan adalah 1, 004 dan nilai probabilitas Tingkat Pengetahuan adalah
0,265. Simpulan uji normalitas data pada Tingkat Pengetahuan adalah normal $(0,265>$ $0,05)$.

Hasil uji kolmogorov-smirnov $z$ pada Tingkat self eficacy 1,097, sedangkan nilai probabilitas pada Tingkat self eficacy adalah 0,180. Simpulan uji normalitas data pada Tingkat self eficacy mahasiswa adalah normal $(0,180>$ $0,05)$.

b. Uji Asumsi

Tabel 5. Uji Asumsi

\begin{tabular}{lllll}
\hline Probabilitas & Residual & VIF & Tolerance & Keputusan \\
\hline 0,020 & 0,000 & 1,000 & 1,000 & linier \\
\hline
\end{tabular}

\section{Sumber: Data Primer 2021}

Uji linieritas digunakan untuk menguji linier tidaknya suatu data yang dianalisis yaitu variabel independen terhadap variabel dependen. Nilai $\mathrm{P}=0,020$.

Nilai mean residual adalah $0,000=0(0,000$ $=0$ ), sehingga asumsi eksistensi terpenuhi.

Uji multikolinearitas bertujuan untuk menguji apakah model regresi ditemukan adanya korelasi yang sempurna antar variabel bebas. Model regresi yang baik seharusnya tidak terjadi korelasi yang sempurna di antara variabel bebas. Salah satu cara untuk mendeteksi adanya multikolinearitas adalah dengan melihat tolerance atau Varians Inflation Factor (VIF). Apabila tolerance lebih kecil dari 0,1 atau nilai VIF di atas 10, maka terjadi multikolinearitas.Hasil uji multikolinearitas 
pada pada tabel di atas diketahui bahwa hasil tolerance pada masing-masing variabel lebih besar dari 0,1 sedangkan nilai Varians Inflation Factor (VIF) lebih kecil dari 10. Sehingga model regresi dalam penelitian ini tidak ada masalah multikolinearitas.

c. Uji Hipotesa
Pengujian hipotesis dalam penelitian ini menggunakan regresi linier analisis ini dimaksudkan untuk mengetahui hubungan variabel-variabel bebas (independen) terhadap variabel terikat atau yang dipengaruhi (dependen). Dikatakan ada hubungan regresional apabila tidak ada true value of $\mathrm{Y}$ untuk nilai $\mathrm{X}$ dan sebaliknya.

Tabel 6. Regresi Sederhana

\begin{tabular}{|c|c|c|c|c|c|}
\hline \multirow{2}{*}{$F_{\text {hitung }}$} & \multicolumn{2}{|c|}{$\mathrm{F}_{\text {table }}$} & \multirow{2}{*}{$\mathrm{t}_{\text {hitung }}$} & \multirow{2}{*}{ P } & \multirow{2}{*}{$\mathrm{R}$} \\
\hline & $5 \%$ & $1 \%$ & & & \\
\hline 0,385 & 4,21 & $\begin{array}{l}7,67 \\
\end{array}$ & 2,480 & 0,540 & 0,119 \\
\hline
\end{tabular}

Sumber: Data Primer 2021

Dari hasil analisis data diketahui bahwa nilai $F$ hitung 0,385. Harga tersebut kemudian dibandingkan dengan harga $F$ tabel dengan $\mathrm{dk}$ penyebut $\mathrm{m}-1$ dan penyebut $\mathrm{N}$-m. dengan demikian dk pembilang 1 dan $\mathrm{dk}$ penyebut 27 . Berdasarkan kedua $\mathrm{dk}$ tersebut maka dapat diketahui $\mathrm{F}_{\text {tabel }}$ untuk 5 $\%$ sebesar 4,21 dan untuk $1 \%$ sebesar 7,67. Ternyata $F_{\text {hitung }}$ lebih kecil dari pada $\mathrm{F}_{\text {tabel }}($ $0,385<4,21<7,67$ ).

Pengujian hipotesis :

Ho : Tidak ada hubungan antara tingkat pengetahuan dengan self efficacy

$\mathrm{Ha}$ : Ada hubungan antara antara tingkat pengetahuan dengan self efficacy

Hasil penelitian $\mathrm{F}_{\text {hitung }}$ lebih kecil dari pada $\mathrm{F}$ tabel $(0,385<4,21<7,67)$. maka disimpulkan Ho diterima dan Ha ditolak. yang artinya tidak ada hubungan antara tingkat pengetahuan dan pendidikan dengan self efficacy.

Uji $R^{2}$ digunakan untuk mengetahui seberapa besar variabel bebas menjelaskan variabel terikat. Nilai koefisien determinasi berkisar antara 0 sampai 1 . Semakin mendekati 1 maka model yang digunakan semakin baik.

Nilai $\mathrm{R}$ pada tingkat pengetahuan dan pendidikan adalah 0,119. Koefisien determinasinya $\mathrm{R}^{2}$ adalah $0,119^{2}=$ 0,014161. Hal ini berarti tingkat pengetahuan akan mempengaruhi self efficacy sebesar $1,41 \%$. Sisanya adalah dipengaruhi oleh faktor lain.

\section{PEMBAHASAN}

Tingkat pendidikan akan mempengaruhi kemampuan seseorang dalam mengolah informasi. Pengetahuan akan membantu ibu dalam merubah perilaku, meningkatkan self efficacy ibu dalam melakukan baby massage dan baby gym. Berdasarkan hasil penelitian didapatkan bahwa sebnyak 11 responden $(37,93 \%)$ memiliki self efficacy yang baik dan berpendidikan akademi/perguruan tinggi. Hal ini menunjukkan bahwa variabel pendidikan ibu memiliki pengaruh signifikan terhadap variabel self efficacy dalam melakukan baby massage dan baby gym. Semakin tinggi pendidikan seseorang maka akan semakin berkualitas pengetahuannya dan semakin matang intelektualnya sehingga memiliki self efficacy yang tinggi pula. Hal ini juga berpengaruh dalam memberikan respon terhadap informasi yang datang dari luar. Mereka yang memiliki pendidikan yang lebih tinggi akan memberikan respon terhadap informasi yang datang dari luar. Mereka yang memiliki pendidikan yang lebih tinggi akan memberikan respon yang rasional dibandingkan mereka yang berpendidikan lebih rendah (Laursen et al, 2008).

Pengetahuan merupakan hasil dari tahu, ini yang terjadi ketika seseorang Pengetahuan akan membantu ibu dalam merubah perilaku, meningkatkan self efficacy ibu dalam melakukan baby massage dan baby gym. Berdasarkan hasil penelitian didapatkan bahwa sebanyak 9 responden $(31,03 \%)$ memiliki self efficacy yang baik dan berpengetahuan sangat baik. Menurut beberapa penelitian besarnya pengaruh factor pengetahuan dapat mempengaruhi self efficacy ibu dalam 
melakukan baby gym dan baby massage. Semakin berkualitas pengetahuannya dan semakin matang intelektualnya sehingga memiliki self efficacy yang tinggi pula. Hal ini juga berpengaruh dalam memberikan respon terhadap informasi yang datang dari luar.

Berdasarkan Tabel 5 Hasil penelitian $F_{\text {hitung }}$ lebih kecil dari pada $F_{\text {tabel }}(0,385<4,21<7,67$ ). maka disimpulkan Ho diterima dan $\mathrm{Ha}$ ditolak. yang artinya tidak ada hubungan antara tingkat pengetahuan dan pendidikan ibu dengan self efficacy dalam melakukan baby massage dan baby gym di desa madegondo kecamatan grogol kabupaten sukoharjo. Meskipun tidak ada hubungan terkait pengetahuan dan Pendidikan terhadap self efficacy ibu dalam melakukan baby massage dan baby gym, berdasarkan hasil uji $\mathrm{R}$ di dapatkan hasil bahwa $\mathrm{Uji} \mathrm{R}^{2}$ yang digunakan untuk mengetahui seberapa besar variabel bebas menjelaskan variabel terikat. Nilai koefisien determinasi berkisar antara 0 sampai 1 . Semakin mendekati 1 maka model yang digunakan semakin baik. Nilai $R$ pada tingkat pengetahuan dan pendidikan adalah 0,119 . Koefisien determinasinya $R^{2}$ adalah $0,119^{2}=0,014161$. Hal ini berarti tingkat pengetahuan dan pendidikan akan mempengaruhi self efficacy sebesar $1,41 \%$. Sisanya adalah dipengaruhi oleh faktor lain.

Menurut peneliti pengetahuan merupakan dasar seseorang untuk melakukan sesuatu dan kunci untuk menimbulkan kepercayaan diri dalam diri seseorang. Pengetahuan dapat diperoleh dari berbagai cara misalnya dengan belajar dan dari pengalaman. Untuk dapat menimbulkan ketertarikan dalam suatu hal maka seseorang membutuhkan suatu pemahaman dalam suatu hal tertentu, sehingga pengetahuan sangat berkaitan dengan self efficacy seseorang. Responden yang masih mempunyai pengetahuan cukup sangat disarankan agar lebih meningkatkan pengetahuannya mengenai baby massage dan baby gym dapat percaya diri dalam mrlakukan baby massage dan baby gym. Semakin banyak pengetahuan yang diperoleh maka akan semakin tinggi kepercayaan diri ibu yang akan tumbuh dalam melakukan baby massage dan baby gym. Hal ini sesuai dengan teori (Rumini, 1998) yang mengatakan bahwa semakin baik pengetahuan maka akan semakin percaya diri dalam melakukan sesuatu, sebaliknya jika pengetahuan kurang maka akan terbentuk kepercayaan diri yang rendah.

\section{SIMPULAN}

Ada pengaruh pengetahuan dan Pendidikan terhadap self efficacy pada ibu dalam melakukan baby gym dan baby massage.

\section{DAFTAR PUSTAKA}

Arikunto, S. 2010. Prosedur Penelitian suatu Pendekatan Praktek. Rineka Cipta. Jakarta

Avey, J. B., Luthans, F., \& Jensen, S. (2009). Psychological Capital: A Positive Resource for Combanting Stress and Tonover. Human Resource Management Bandura, (1994) Self Efficacy In Encyclopedia of Human Behaviour. Ed. Ramachaudran, V.S. Vol. 4, 71-81. New York: Academic Press .(1997). Self Efficacy in Changing Societies. Inggris: Cambridge University Press.

.(2001). Social Cognitive Theory of Mass Communication, Media Physhology, Vol.3

Depkes. RI. (2013). Riset Dasar. Jakarta: Badan Penelitian dan Pengembangan Kesehatan Kementrian Kesehatan. RI.

Dewi, Siska. 2012. Pijat dan asupan gizi tepat. Ed.ke-1.Pustaka Baru Press. Yogyakarta.

Feist, J. \& Feist, G.J. (2008). Theories of Personality. (6th). Yogyakarta: Putaka Pelajar

Field, Tiffany. 2011. Complementary Therapies in Clinical Practice. Elsevier volume 17 (2011) pp 1-8

Laursen, E.K. 2008. Rather Than Fixing Kids Build Positive Peer Cultures Reclaming Children and Youth. (ProQuest Education Journals)

Leahy-Warren, P., (2005). Frist timr mothers: Social support and counfidance in Infant Care. Journal of Advance Nursing

Roesli, U. 2008. Inisiasi Menyusu Dini Plus ASI Eksklusif .Jakarta : Pustaka Bunda

Rumini, S. 1998. Psikologi Pendidikan. Yogyakarta: UNY Press

Walker, Peter. (2011). Panduan Lengkap Pijat Bayi. Depok: Puspa Swara. 